\title{
PbS Quantum Dots-Induced Trap-Assisted Charge Injection in Perovskite
}

\author{
Photodetectors \\ Chang Liu, Hui Peng, Kai Wang, Chunding Wei, Zixin Wang and Xiong Gong* \\ Department of Polymer Engineering, College of Polymer Science and Polymer Engineering, \\ The University of Akron, Akron, OH 44325, USA
}

\begin{abstract}
In this study, we report solution-processed photodetectors fabricated by methylammonium triiodide perovskite $\left(\mathrm{CH}_{3} \mathrm{NH}_{3} \mathrm{PbI}_{3}\right)$ incorporated with $\mathrm{PbS}$ quantum dots (QDs) through the trapassisted charge-injection effect. In order to increase the photo-responsivity by eliminating the charge injection barrier from the cathode electrode, $\mathrm{PbS}$ QDs, which possesses large amount of trap states, are introduced into the $\mathrm{CH}_{3} \mathrm{NH}_{3} \mathrm{PbI}_{3}$ thin film for establishing ohmic contact at the $\mathrm{CH}_{3} \mathrm{NH}_{3} \mathrm{PbI}_{3}$ /aluminum (Al) interface. As a result, an external quantum efficiency of $\sim 4500 \%$, a photoresponsivity of $\sim 15000 \mathrm{~mA} / \mathrm{W}$ and a detectivity of over $6 \times 10^{13}$ Jones (1 Jones=1 $\mathrm{cmHz}^{1 / 2} \mathrm{~W}^{-1}$ ) at a small bias of 2 volts, and a photoresponse time of $11.5 \mu \mathrm{s}$ are observed from the solution-processed photodetectors fabricated by the $\mathrm{CH}_{3} \mathrm{NH}_{3} \mathrm{PbI}_{3}: \mathrm{PbS}$ QDs nanocomposites thin film.
\end{abstract}

*Corresponding author, Email: xgong@ uakron.edu; Fax: (330)9723406 


\section{Introduction}

The trap-assisted charge-injection process, which evolves the trapping of one type of charge carrier at the semiconductor / metal electrode interface and the injection of the opposite charge through the corresponding electrode to compromise small dielectric constants and low charge carrier mobility of polymers [1,2], has been intensively applied for boosting the external quantum efficiencies (EQEs) of polymer based photodetectors (PDs) in the past years [3-9]. In polymer PDs, a trace amount of fullerene derivatives or inorganic nanoparticles (or quantum dots (QDs)) was introduced as the electron trapping sites, which would lower down the lowest unoccupied molecular orbital (LUMO) energy level of polymer and induce the fermi-level alignment at the polymer / cathode interface, thus assisting energy-barrierless hole-injection from the cathode and consequently boosting the EQEs [3-9]. However, the photoresponse time of this type of polymer PDs has yet to plateau on account of the low charge carrier mobility of polymers, which are usually on the scale of millisecond (ms) [4,6,9]. In addition, the biases required for achieving decent EQEs are usually as high as $10 \mathrm{~V}$ [3-9]. The slow photoresponse and high output voltages would substantially restrict these polymer PDs in the applications of chemical/biological sensing, communications, etc., where high-speed and low-power PDs are required.

In order to enhance the photoresponse speed and lower down the output voltages, we, in this study, utilize the organometallic halide perovskite hybrid materials, $\mathrm{CH}_{3} \mathrm{NH}_{3} \mathrm{PbI}_{3}$, incorporated with lead sulfide $(\mathrm{PbS}) \mathrm{QDs}$, as the active layer through the trap-assisted charge-injection effect to develop next generation of PDs with ultra-high photo-gains. Perovskite hybrid materials are selected because they possess numerous intrinsic trap states on the surface and grain boundaries, large charge carrier mobility, long carrier diffusion length and high absorption coefficient [1019]. These advanced features would enable the perovskite hybrid PDs (pero-HPDs) exhibiting 
the high-speed photoresponse and large photo-gain through high electrical conductive PbS QDs as additional trap states into the $\mathrm{CH}_{3} \mathrm{NH}_{3} \mathrm{PbI}_{3}$ active layer [20-23] under low output voltages. Moreover, by tuning the PbS QDs size, the LUMO energy level of PbS QDs can be easily achieved [24,25], which would capture the photo-generated electrons in the $\mathrm{CH}_{3} \mathrm{NH}_{3} \mathrm{PbI}_{3}$ layer, resulting in down-shifted conduction band minimum $(\mathrm{CBM})$ of the $\mathrm{CH}_{3} \mathrm{NH}_{3} \mathrm{PbI}_{3}: \mathrm{PbS}$ QDs nanocomposites at the interface between the $\mathrm{CH}_{3} \mathrm{NH}_{3} \mathrm{PbI}_{3}: \mathrm{PbS}$ QDs nanocomposites and $\mathrm{Al}$ cathode. Through the fermi-level of the $\mathrm{CH}_{3} \mathrm{NH}_{3} \mathrm{PbI}_{3}: \mathrm{PbS}$ QDs nanocomposites re-alignment with the work function of the cathode, energy barrier for hole-injection can thus be effectively decreased. As a result, a significantly enhanced EQE ( 4500\%), an increased responsivity (R) $(\sim 15000 \mathrm{~mA} / \mathrm{W})$ and a boosted detectivity $\left(\mathrm{D}^{*}\right)\left(\sim 6 \times 10^{13}\right.$ Jones, 1 Jones $\left.=1 \mathrm{cmHz}^{1 / 2} \mathrm{~W}^{-1}\right)$ under low bias $(-2 \mathrm{~V})$ at room temperature are observed from the pero-HPDs fabricated by the $\mathrm{CH}_{3} \mathrm{NH}_{3} \mathrm{PbI}_{3}$ incorporated with $\mathrm{PbS}$ QDs thin film.

\section{Results and discussion}

Scheme 1a displays the device structure of pero-HPDs, where ITO is indium tin oxide as the anode electrode, PEDOT:PSS is poly(3,4-ethylenedioxythiophene) polystyrene sulfonate as the hole-extraction layer, phenyl-C61-butyric acid methyl ester/bathocuproine $\left(\mathrm{PC}_{61} \mathrm{BM} / \mathrm{BCP}\right)$ bilayer is the hole-blocking layer, and $\mathrm{Al}$ is aluminum as the cathode electrode. Schemes $1 \mathrm{~b} \& 1 \mathrm{c}$ illustrate the working mechanism of the pero-HPDs by the trap-assisted hole-injection process, both in dark and under light illumination, respectively. In the absence of illumination, the holes are difficult to be injected from the $\mathrm{Al}$ cathode into the of either the valence band maximum (VBM) of $\mathrm{CH}_{3} \mathrm{NH}_{3} \mathrm{PbI}_{3}$ thin film or the highest occupied molecular orbital (HOMO) energy levels PbS QDs thin film due to large hole-injection energy barrier. Thus, the dark current of pero-HPDs is very small since pero-HPDs is a typical Schottky diode. However, as shown in 
Scheme 1c, under illumination, the excitons formed in the $\mathrm{CH}_{3} \mathrm{NH}_{3} \mathrm{PbI}_{3}$ layer would rapidly dissociate into electrons and holes, and then separated holes would be extracted and collected by the ITO anode; while the separated electrons would be migrated through the $\mathrm{PC}_{61} \mathrm{BM} / \mathrm{BCP}$ bilayer and collected by the $\mathrm{Al}$ cathode. Due to the large amount of intrinsic trap states within the $\mathrm{CH}_{3} \mathrm{NH}_{3} \mathrm{PbI}_{3}$ thin film and $\mathrm{PbS}$ QDs induced traps resided on the surface of the $\mathrm{CH}_{3} \mathrm{NH}_{3} \mathrm{PbI}_{3}$ thin film, the separated electrons would be trapped at the $\mathrm{CH}_{3} \mathrm{NH}_{3} \mathrm{PbI}_{3}: \mathrm{PbS}$ QDs nanocomposites surface, which would shift the CBM energy level and the fermi level of the $\mathrm{CH}_{3} \mathrm{NH}_{3} \mathrm{PbI}_{3}: \mathrm{PbS}$ QDs nanocomposites (near the surface) downwards quickly, followed by the re-alignment of its fermi level with the work function of the Al electrode. In addition, the trapped electrons can be considered as heavy-doping on the surface of the $\mathrm{CH}_{3} \mathrm{NH}_{3} \mathrm{PbI}_{3}: \mathrm{PbS}$ QDs nanocomposites layer, which dramatically narrow the depletion region formed at the interface. Thus, once the fermi level of the nanocomposites is pinned with the work function of the Al cathode, the injected holes from the $\mathrm{Al}$ cathode can be easily tunneled through the $\mathrm{PC}_{61} \mathrm{BM} / \mathrm{BCP}$ bilayer at low external biases [1-5], resulting in high EQEs. The working principles of the pero-HPDs fabricated by pristine $\mathrm{CH}_{3} \mathrm{NH}_{3} \mathrm{PbI}_{3}$ thin film are also shown in Scheme S1a (in Supplementary Information, SI) for comparison. According to Scheme 1a, small amount of intrinsic traps on the $\mathrm{CH}_{3} \mathrm{NH}_{3} \mathrm{PbI}_{3}$ thin film surface would capture the photo-generated electrons, which slightly down-shift the $\mathrm{CBM}$ and fermi level of the $\mathrm{CH}_{3} \mathrm{NH}_{3} \mathrm{PbI}_{3}$ layer near the surface, followed by the fermi level pinning between the $\mathrm{CH}_{3} \mathrm{~N}_{3} \mathrm{HPbI}_{3}$ layer (near the surface) and Al. However, it's seen that the hole-injection barrier is still very large due to the limited trapped electron density, as comparison with that of the pero-HPDs fabricated by the $\mathrm{CH}_{3} \mathrm{NH}_{3} \mathrm{PbI}$ : $\mathrm{PbS}$ QDs nanocomposites layer (Scheme S1b), which predicts much lower hole-injection currents and EQEs under external biases. 
In order to verify above hypothesis, thin film morphologies of the $\mathrm{CH}_{3} \mathrm{NH}_{3} \mathrm{PbI}_{3}$ layer and the $\mathrm{CH}_{3} \mathrm{NH}_{3} \mathrm{PbI}_{3}: \mathrm{PbS}$ QDs nanocomposites (with a weight ratio of 30:1, 30:2 and 30:3) layers are studied by the Scanning Electron Microscope (SEM) images. The results are shown in Fig. S1a-d. These results reveal significant differences in the thin film surface morphologies. Large amount of $\mathrm{PbS}$ QDs are indeed resided on the surface of the $\mathrm{CH}_{3} \mathrm{NH}_{3} \mathrm{PbI}_{3}$ thin film. These PbS QDs can capture the photo-generated electrons, assisting the energy barrierless hole-injection from the Al cathode. However, further increasing $\mathrm{PbS}$ QDs into the $\mathrm{CH}_{3} \mathrm{NH}_{3} \mathrm{PbI}_{3}$ thin film, for instance, to a weight ratio of 30:3, would severely sacrifices the thin film morphology (Fig. S1d in SI). Such inferior film morphology would result in poor device performance, which makes it difficult for valid EQE measurement.

The trap densities of state (t-DOS) of the $\mathrm{CH}_{3} \mathrm{NH}_{3} \mathrm{PbI}_{3}: \mathrm{PbS}$ QDs nanocomposites thin films are compared with that of the $\mathrm{CH}_{3} \mathrm{NH}_{3} \mathrm{PbI}_{3}$ thin film for further verification of above hypothesis. The t-DOS of the $\mathrm{CH}_{3} \mathrm{NH}_{3} \mathrm{PbI}_{3}: \mathrm{PbS}$ QDs nanocomposites thin film is determined from the chemical capacitance $\left(C_{\mu}\right)$ at the open-circuit voltage $\left(\mathrm{V}_{\mathrm{OC}}\right)$ under different illumination intensities [21,26]. Details of the t-DOS measurements were illustrated in SI. The device structure of ITO/PEDOT:PSS/CH${ }_{3} \mathrm{NH}_{3} \mathrm{PbI}_{3}$ ( or $\mathrm{CH}_{3} \mathrm{NH}_{3} \mathrm{PbI}_{3}: \mathrm{PbS}$ QDs)/PC 61 BM/BCP/Al, where $\mathrm{PC}_{61} \mathrm{BM}$ layer with a large thickness $(\sim 80 \mathrm{~nm})$ for obtaining a photodiode under illumination [17], is applied for determining the $C_{\mu}$ values. Thus a measurable $\mathrm{V}_{\mathrm{OC}}$ under various illumination intensities would be ensured for extracting the t-DOS from the capacitance-voltage $(\mathrm{C}-\mathrm{V})$ characteristics. Noted that the $\mathrm{C}-\mathrm{V}$ characteristics measurement is not aimed to provide precise $\mathrm{t}-$ DOS values for the $\mathrm{CH}_{3} \mathrm{NH}_{3} \mathrm{PbI}_{3}$ and $\mathrm{CH}_{3} \mathrm{NH}_{3} \mathrm{PbI}_{3}$ :PbS QDs nanocomposites thin films under the operational condition of pero-HPDs, but rather to investigate the effect of PbS QDs on the tDOS of the $\mathrm{CH}_{3} \mathrm{NH}_{3} \mathrm{PbI}_{3}$ thin film, since the $\mathrm{PC}_{61} \mathrm{BM}$ layer would passivate large amount of the 
trap states in both $\mathrm{CH}_{3} \mathrm{NH}_{3} \mathrm{PbI}_{3}$ and $\mathrm{CH}_{3} \mathrm{NH}_{3} \mathrm{PbI}_{3}: \mathrm{PbS}$ QDs nanocomposites thin films. The tDOS distributions of the $\mathrm{CH}_{3} \mathrm{NH}_{3} \mathrm{PbI}_{3}$ and the $\mathrm{CH}_{3} \mathrm{NH}_{3} \mathrm{PbI}_{3}: \mathrm{PbS}$ QDs (weight ratio of 30:1 and 30:2) nanocomposites thin films are illustrated in Fig. 1a. It's observed that the t-DOS is significantly increased with the increased $\mathrm{PbS}$ QDs weight ratio, reaching fourfold higher values of the t-DOS upon the addition of PbS QDs in the $\mathrm{CH}_{3} \mathrm{NH}_{3} \mathrm{PbI}_{3}$ thin film at a weight ratio of 30:2. The distribution of $t-D O S$ is then fitted by Gaussian equation:

$$
g_{n}\left(E-E_{L}\right)=\frac{N_{n}}{\sqrt{2 \pi \sigma_{n}}} \exp \left[-\frac{\left(E_{L}-E\right)^{2}}{2 \sigma_{n}^{2}}\right][27]
$$

where $\mathrm{E}$ is the fermi level, $E_{L}$ is the energy center of the t-DOS, $N_{n}$ is the total density per unit volume and $\sigma_{n}$ is the disorder parameter that represents the broadness of the t-DOS. The devices fabricated by the $\mathrm{CH}_{3} \mathrm{NH}_{3} \mathrm{PbI}_{3}: \mathrm{PbS}$ QDs nanocomposites thin films exhibit a wide t-DOS distribution with a $\sigma_{n}$ of $200 \mathrm{meV}$ and $230 \mathrm{meV}$ for the $\mathrm{CH}_{3} \mathrm{NH}_{3} \mathrm{PbI}_{3}: \mathrm{PbS}$ QDs nanocomposites with a weight ratio of 30:1 and 30:2, respectively, whereas the device fabricated by the $\mathrm{CH}_{3} \mathrm{NH}_{3} \mathrm{PbI}_{3}$ thin film shows a much narrower distribution with a $\sigma_{n}$ of $142 \mathrm{meV}$. As schematically illustrated in Fig. 1b, a wider t-DOS distribution along with larger amount of $N_{n}$ declares that PbS QDs indeed induce numerous additional traps at various in-gap energy levels (from shallow to deep) into the $\mathrm{CH}_{3} \mathrm{NH}_{3} \mathrm{PbI}_{3}$ thin film, among which, the deep traps (located at low $\mathrm{V}_{\mathrm{OC}}$ ) will effectively capture the electrons under reverse biases. Therefore, dramatically enhanced photo-responsivities are expected from the pero-HPDs fabricated by the $\mathrm{CH}_{3} \mathrm{NH}_{3} \mathrm{PbI}_{3}: \mathrm{PbS}$ QDs nanocomposites thin films as a result of lower energy barrier for holeinjection from the Al cathode.

The EQEs are investigated to study the effect of photo-gains by PbS QDs in pero-HPDs. Fig. 2a presents the EQEs versus wavelength of the pero-HPDs fabricated by either the $\mathrm{CH}_{3} \mathrm{NH}_{3} \mathrm{PbI}_{3}$ thin film or the $\mathrm{CH}_{3} \mathrm{NH}_{3} \mathrm{PbI}_{3}$ :PbS QDs nanocomposites thin film. The EQE value of the pero- 
HPDs fabricated by the $\mathrm{CH}_{3} \mathrm{NH}_{3} \mathrm{PbI}_{3}$ thin film is exceeded $100 \%$ at $-1 \mathrm{~V}$, and gradually increased as further enhanced reverse biases, reaching $240 \%$ at $-2 \mathrm{~V}$. The EQE values over unit indicates that the LUMO energy levels of the $\mathrm{CH}_{3} \mathrm{NH}_{3} \mathrm{PbI}_{3}$ thin film is tuned by the intrinsic traps on its surface, thus assisting the hole-injection from the cathode electrode. It's notable that a thin layer of $\mathrm{PC}_{61} \mathrm{BM}$, which functions as the hole-blocking layer, would inevitably passivate small amount of traps on the surface of the $\mathrm{CH}_{3} \mathrm{NH}_{3} \mathrm{PbI}_{3}$ thin film, consequently enlarging the energy barrier at the $\mathrm{CH}_{3} \mathrm{NH}_{3} \mathrm{PbI}_{3} / \mathrm{Al}$ interface and causing photocurrent losses. Yet low dark currents are indispensable for PDs with high detectivity [28,29], introducing additional traps for adjusting the fermi level alignment turns out to be one of the most effective ways to increase the photo-gain while maintaining low dark currents. It is noticed from Fig. 2a that the EQE values are significantly increased with the introduction of PbS QDs-induced traps at a weight ratio of 30:2 for $\mathrm{CH}_{3} \mathrm{NH}_{3} \mathrm{PbI}_{3}$ to $\mathrm{PbS}$ QDs. The EQE value exceeds $100 \%$ at a dramatically lower reverse bias $(<-0.5 \mathrm{~V})$ and rapidly enhances with external electric field, reaching the highest $\mathrm{EQE}$ of $\sim 3200 \%$ at $-2 \mathrm{~V}$. These results are in good agreement with the increased photocurrent with negative biases as shown in Fig. $2 b$, in which a drastic photocurrent raise is occurred at $\sim-0.5 \mathrm{~V}$. In order to study the effects of the t-DOS on the photo-gain of pero-HPDs, the EQE spectra of the peroHPD fabricated by the $\mathrm{CH}_{3} \mathrm{NH}_{3} \mathrm{PbI}_{3}: \mathrm{PbS}$ QDs (30:1) nanocomposites thin film are also measured for comparison study. The results are shown in Fig. S3 in SI. Under the same external biases, the EQE values are large than that from the pero-HPDs fabricated by the $\mathrm{CH}_{3} \mathrm{NH}_{3} \mathrm{PbI}_{3}$ thin film and smaller than that from the pero-HPDs fabricated by the $\mathrm{CH}_{3} \mathrm{NH}_{3} \mathrm{PbI}_{3}: \mathrm{PbS}$ QDs (30:2) nanocomposites thin film, indicating that the incremented trap states with enhanced amount of PbS QDs (Fig. 1) down-shift the LUMO energy level of the $\mathrm{CH}_{3} \mathrm{NH}_{3} \mathrm{PbI}_{3}$ thin film more steeply, thus reducing the energy barrier and increasing the hole-injection current from the $\mathrm{Al}$ cathode. 
In addition, it's observed from Fig. $2 b$ that the pero-HPDs fabricated by the $\mathrm{CH}_{3} \mathrm{NH}_{3} \mathrm{PbI}_{3}: \mathrm{PbS}$ QDs (weight ratio 30:2) nanocomposites thin film shows low reverse-bias dark currents, indicating the small amount of PbS QDs addition would not cause current leakage in pero-HPDs. Therefore, the J-V characteristics shown in Fig. 2b illustrate that the light functions as a "valve" for switching pero-HPDs from a photodiode in dark to a photoconductor under illumination. In contrast to the Schottcky junction in a photodiode, the PbS QDs-induced trap-assisted ohmic contact is formed between the $\mathrm{CH}_{3} \mathrm{NH}_{3} \mathrm{PbI}_{3}$ thin film and the $\mathrm{Al}$ cathode, which gives rise to the abundant injected charges. Whereas the hole-blocking layer $\left(\mathrm{PC}_{61} \mathrm{BM} / \mathrm{BCP}\right)$, which is applied to depress the dark currents, would create hole-injection barrier and cause photocurrent losses. As a result, as the hole-blocking barrier $\left(\mathrm{PC}_{61} \mathrm{BM} / \mathrm{BCP}\right)$ is eliminated, the maximum $\mathrm{EQE}$ value from the pero-HPDs fabricated by the $\mathrm{CH}_{3} \mathrm{NH}_{3} \mathrm{PbI}_{3}: \mathrm{PbS}$ QDs (weight ratio 30:2) nanocomposites thin film is further enhanced over $4500 \%$ at $-2 \mathrm{~V}$ (Fig. S4a in SI), in comparison with those ( 3200\%) from the pero-HPDs with the hole-blocking layer (Fig. 2a). However, the dark currents shown in Fig. S4b in SI are tremendously higher than those from the pero-HPDs fabricated by the $\mathrm{CH}_{3} \mathrm{NH}_{3} \mathrm{PbI}_{3}: \mathrm{PbS}$ QDs (weight ratio 30:2) nanocomposites thin film with the hole-blocking layers (Fig. 2b), manifesting the necessity of the hole-blocking layers for high detective PDs.

In order to further validate the working mechanism depicted in Schemes $1 \mathrm{a} \& 1 \mathrm{~b}$, the hole injection current ( $\mathrm{J}$ ) of the pero-HPDs fabricated either by the $\mathrm{CH}_{3} \mathrm{NH}_{3} \mathrm{PbI}_{3}$ thin film or by the $\mathrm{CH}_{3} \mathrm{NH}_{3} \mathrm{PbI}_{3}: \mathrm{PbS}$ QDs nanocomposites thin film under various illumination intensities of white light and monochromatic light at the wavelength $(\lambda)$ of $500 \mathrm{~nm}$ are investigated. Based on the Richardson-Dushman equation of $\mathrm{J} \propto \exp \left(-\frac{\Delta \Phi}{k T}\right) \propto \exp \left(\frac{n_{t}}{k T}\right)$ [30], where J is the injection current density, $\Delta \Phi$ is the energy barrier change, $n_{t}$ is the trapped electron density, $\mathrm{k}$ is the Boltzmann constant and $\mathrm{T}$ is the temperature, $\Delta \Phi$ has a linear function with $n_{t}$, and $\mathrm{J}$ shows an 
exponential relationship with $n_{t}$. In principal, the intensified illumination irradiance would increase $n_{t}$ in both $\mathrm{CH}_{3} \mathrm{NH}_{3} \mathrm{PbI}_{3}$ and $\mathrm{CH}_{3} \mathrm{NH}_{3} \mathrm{PbI}_{3}: \mathrm{PbS}$ QDs nanocomposites thin films, which would exponentially increase J. It's observed from Fig. 2c that the pero-HPDs fabricated by either $\mathrm{CH}_{3} \mathrm{NH}_{3} \mathrm{PbI}_{3}$ thin film or the $\mathrm{CH}_{3} \mathrm{NH}_{3} \mathrm{PbI}_{3}$ : $\mathrm{PbS}$ QDs nanocomposites thin film show a linear function of $\log \mathrm{J}$ with white light irradiance, indicating the trap-assisted charge-injection process is applied in both devices. It's also found that the pero-HPDs fabricated by the $\mathrm{CH}_{3} \mathrm{NH}_{3} \mathrm{PbI}_{3}: \mathrm{PbS}$ QDs nanocomposites thin film exhibits larger slope than that of pero-HPDs fabricated by pristine $\mathrm{CH}_{3} \mathrm{NH}_{3} \mathrm{PbI}_{3}$ thin film, with smaller $\mathrm{J}$ under weak light intensities (less than $10^{-3} \mathrm{~mW} / \mathrm{cm}^{2}$ ). For the pero-HPDs fabricated by the $\mathrm{CH}_{3} \mathrm{NH}_{3} \mathrm{PbI}_{3}: \mathrm{PbS}$ QDs nanocomposites thin film, under weak light intensity (less than $10^{-3} \mathrm{~mW} / \mathrm{cm}^{2}$ ), there's only slight CBM shift due to the low trapped electron density, the large energy barrier still limits the hole-injection process. Whereas, in pristine $\mathrm{CH}_{3} \mathrm{NH}_{3} \mathrm{PbI}_{3}$ thin film, where the quantity of the intrinsic trap states after $\mathrm{PC}_{61} \mathrm{BM}$ passivation is not so significant, some of the photo-generated electrons can also be collected by the electrode, aside from being trapped. This part of the electrons could contribute to the photocurrents which are higher than the hole-injection currents in pero-HPDs fabricated by pristine $\mathrm{CH}_{3} \mathrm{NH}_{3} \mathrm{PbI}_{3}$ thin film. But with the light intensity increasing, owing to the larger amount of traps in the $\mathrm{CH}_{3} \mathrm{NH}_{3} \mathrm{PbI}_{3}: \mathrm{PbS}$ QDs nanocomposites thin film than that in $\mathrm{CH}_{3} \mathrm{NH}_{3} \mathrm{PbI}_{3}$ thin film, the CBM and the fermi level down-shifts would be much steeper in the pero-HPDs fabricated by the $\mathrm{CH}_{3} \mathrm{NH}_{3} \mathrm{PbI}_{3}: \mathrm{PbS}$ QDs nanocomposites thin film than those in pero-HPDs fabricated by pristine $\mathrm{CH}_{3} \mathrm{NH}_{3} \mathrm{PbI}_{3}$ thin film, which results in lower hole-injection barrier and consequently higher hole-injection current in the pero-HPDs fabricated by the $\mathrm{CH}_{3} \mathrm{NH}_{3} \mathrm{PbI}_{3}: \mathrm{PbS}$ QDs nanocomposites thin film. Under such condition, the hole-injection current in pero-HPDs fabricated by the $\mathrm{CH}_{3} \mathrm{NH}_{3} \mathrm{PbI}_{3}: \mathrm{PbS}$ QDs nanocomposites thin film also notably exceeds the 
photocurrent originated the photo-generated electrons in pristine pero-HPDs. Thus higher $\mathbf{J}$ was observed from the pero-HPDs fabricated by the $\mathrm{CH}_{3} \mathrm{NH}_{3} \mathrm{PbI}_{3}$ : $\mathrm{PbS}$ QDs nanocomposites thin film under higher light intensities, which results in the larger slope of the logarithmically linear relationship. Fig. 2d shows the $\mathrm{J}$ as a function of illumination intensity of a monochromatic light at $\lambda=500 \mathrm{~nm}$, the linear relation between $\mathrm{J}$ and the light intensities insinuate that the trap-assisted hole-injection process takes place in pero-HPDs. As a result, the proposed working mechanism of the pero-HPDs fabricated by the $\mathrm{CH}_{3} \mathrm{NH}_{3} \mathrm{PbI}_{3}$ : $\mathrm{PbS}$ QDs nanocomposites thin film, as shown in Scheme 1, is further validated.

An interesting observation from Fig. $2 b$ is that the dark current densities under the reversebiases from the pero-HPDs fabricated by the $\mathrm{CH}_{3} \mathrm{NH}_{3} \mathrm{PbI}_{3}: \mathrm{PbS}$ QDs nanocomposites thin film are even lower than those from the pero-HPDs fabricated by the $\mathrm{CH}_{3} \mathrm{NH}_{3} \mathrm{PbI}_{3}$ thin film. To gain a deeper insight into this phenomenon, the $\mathrm{CH}_{3} \mathrm{NH}_{3} \mathrm{PbI}_{3}$ and the $\mathrm{CH}_{3} \mathrm{NH}_{3} \mathrm{PbI}_{3}: \mathrm{PbS}$ QDs nanocomposites thin films are investigated by grazing-incidence wide-angle X-ray scattering (GIWAX), the results are shown in Fig. 3. The additional scattering rings exhibited in Fig. $3 b$ in the small angle region from $\mathrm{q}=0.10 \AA^{-1}$ to $\mathrm{q}=0.16 \AA^{-1}$, as well as in the large angle region from $\mathrm{q}=2.10 \AA^{-1}$ to $\mathrm{q}=2.25 \AA^{-1}$ are from the crystallization of PbS QDs [31,32]. Azimuthally integrating the scattering intensities over the scattering vector $q$ (where $q=4 \pi \sin \theta / \lambda, \theta$ is the half of the scattering angle, $\lambda=0.116 \mathrm{~nm}$ is the $\mathrm{X}$-ray wavelength) affords the GIWAX patterns. Fig. 3c shows that with the addition of PbS QDs, shaper peaks with smaller full width at half maximum (FWHM) are obtained at $\mathrm{q}=1.04 \AA^{-1}$ and $\mathrm{q}=2.32 \AA^{-1}$, accompanied by the elimination of small shoulders, which indicates the formation of finer perovskite crystals with fewer lowdimensional defects [33]. Thus, dark currents originated from the defect leakage would be reduced, predicting higher detectivities in the pero-HPDs fabricated by the $\mathrm{CH}_{3} \mathrm{NH}_{3} \mathrm{PbI}_{3}: \mathrm{PbS}$ 
QDs nanocomposites thin film than those from the pero-HPDs fabricated by the $\mathrm{CH}_{3} \mathrm{NH}_{3} \mathrm{PbI}_{3}$ thin film.

Fig. $2 \mathrm{~b}$ presents the current density versus voltage (J-V) characteristics of pero-HPDs measured at room temperature under the illumination of monochromatic light at $\lambda=500 \mathrm{~nm}$ with a light intensity of $1.15 \mathrm{~mW} / \mathrm{cm}^{2}$. The photocurrent $\left(\mathrm{J}_{\mathrm{ph}}\right)$ and dark current $\left(\mathrm{J}_{\mathrm{d}}\right)$ densities under the external biases of $-0.5 \mathrm{~V},-1 \mathrm{~V}$ and $-2 \mathrm{~V}$ are summarized in Table 1 . The responsivity $(\mathrm{R})$ and the detectivity $\left(D^{*}\right)$, which are used to evaluate PDs, are estimated according to the equations of $\mathrm{R}=\frac{J_{p h}}{L_{\text {light }}}[34]$ (where $J_{p h}$ is the photocurrent and $L_{\text {light }}$ is the incident light intensity) and $D^{*}=R / \sqrt{2 q J_{d}}[34]$ (where $J_{d}$ is the dark current density, $\mathrm{q}$ is the elementary electric charge, $\mathrm{q}=1.6 \times 10^{-19} \mathrm{C}$ ), respectively. $\mathrm{R}$ and $D^{*}$ of pero-HPDs under various external biases at $\lambda=500 \mathrm{~nm}$ are also summarized in Table 1. It's found that $\mathrm{R}$ of the pero-HPDs fabricated by the $\mathrm{CH}_{3} \mathrm{NH}_{3} \mathrm{PbI}_{3}: \mathrm{PbS}$ QDs nanocomposites thin film under reverse biases are nearly 10 times higher than those of the pero-HPDs fabricated by the $\mathrm{CH}_{3} \mathrm{NH}_{3} \mathrm{PbI}_{3}$ thin film. These observations are consistent with the EQE values shown in Fig. 2a. Owing to both increased $\mathrm{J}_{\mathrm{ph}}$ and reduced $\mathrm{J}_{\mathrm{d}}, D^{*}$ at $\lambda=500 \mathrm{~nm}$, for the pero-HPDs fabricated by the $\mathrm{CH}_{3} \mathrm{NH}_{3} \mathrm{PbI}_{3}: \mathrm{PbS}$ QDs nanocomposites thin film is estimated to be $\sim 2 \times 10^{13}$ Jones, which is over one order of magnitude higher than that $\left(\sim 1.5 \times 10^{12}\right.$ Jones $)$ of the pero-HPDs fabricated by the $\mathrm{CH}_{3} \mathrm{NH}_{3} \mathrm{PbI}_{3}$ thin film. It's also noticed that the pero-HPDs fabricated by the $\mathrm{CH}_{3} \mathrm{NH}_{3} \mathrm{PbI}_{3}$ : $\mathrm{PbS}$ QDs nanocomposites thin film exhibit over 10 times higher $\mathrm{R}$ than that from the Si-based PDs [35] under weak electric field, with comparable $D^{*}$ on the same order of magnitude, which expresses that the pero-HPDs by the trapassisted hole-injection process could be a simple and inexpensive alternative for conventional Sibased PDs. 
According to the EQE spectra of the pero-HPDs fabricated by either the $\mathrm{CH}_{3} \mathrm{NH}_{3} \mathrm{PbI}_{3}$ thin film or the $\mathrm{CH}_{3} \mathrm{NH}_{3} \mathrm{PbI}_{3}: \mathrm{PbS}$ QDs nanocomposites thin film, $D^{*}$ and $\mathrm{R}$ as a function of wavelength at different external biases are estimated based on the equation of $\mathrm{R}=E Q E \times \frac{q}{h v}=E Q E \times \frac{q \lambda}{h c}=$ $E Q E \times \frac{\lambda}{1240}[34]$ (where $\mathrm{h}$ is the planck's constant, $v$ is the frequency of the incident light, $\mathrm{c}$ is the light speed in vacuum), the results are shown in Fig. 4a,b. It's found that the overall R values of the pero-HPDs fabricated by the $\mathrm{CH}_{3} \mathrm{NH}_{3} \mathrm{PbI}_{3}$ thin film in the visible to near infrared (NIR) region are increased from $\sim 500 \mathrm{~mA} / \mathrm{W}$ at $-0.5 \mathrm{~V}$ to $\sim 1000 \mathrm{~mA} / \mathrm{W}$ at $-2 \mathrm{~V}$. The much higher $\mathrm{R}$ values than those from the Schottky diodes is attributed to the trap-assisted hole-injection caused by the intrinsic traps on the $\mathrm{CH}_{3} \mathrm{NH}_{3} \mathrm{PbI}_{3}$ thin film surface. With the introduction of additional PbS QDs-induced traps, $\mathrm{R}$ values of the pero-HPDs fabricated by the $\mathrm{CH}_{3} \mathrm{NH}_{3} \mathrm{PbI}_{3}: \mathrm{PbS}$ QDs nanocomposites thin film are increased by one order of magnitude in the whole visible to NIR region, reaching $\sim 3000 \mathrm{~mA} / \mathrm{W}$ at $-0.5 \mathrm{~V}$ and $\sim 15000 \mathrm{~mA} / \mathrm{W}$ at $-2 \mathrm{~V}$, respectively. $D^{*}$ of the peroHPDs fabricated by the $\mathrm{CH}_{3} \mathrm{NH}_{3} \mathrm{PbI}_{3}$ thin film in the visible to NIR region are reduced from $\sim 3 \times 10^{12}$ Jones to $\sim 1 \times 10^{12}$ Jones as the biases increasing from $-0.5 \mathrm{~V}$ to $-2 \mathrm{~V}$, which is attributed to the enlarged dark current densities at high external biases through the leakage pathways formed in the $\mathrm{CH}_{3} \mathrm{NH}_{3} \mathrm{PbI}_{3}$ thin film. In the pero-HPDs fabricated by the $\mathrm{CH}_{3} \mathrm{NH}_{3} \mathrm{PbI}_{3}: \mathrm{PbS}$ QDs nanocomposites thin film, the simultaneously improved photocurrent and restricted dark current (in Fig. 2b) results in the dramatically enhanced $D^{*}$ by over one order of magnitude enhancement, achieving $\sim 6 \times 10^{13}$ Jones at $-0.5 \mathrm{~V}$ and $3 \times 10^{13}$ at $-2 \mathrm{~V}$, respectively. These values are among one of the highest $\mathrm{R}$ and $D^{*}$ from the reported pero-HPDs [36-41], demonstrating the trap-assisted charge injection is a favorable methodology for realizing highly sensitive PDs at low output voltages. 
The photocurrent densities versus the incident light intensities are further characterized. Based on the results shown in Fig. 4c, the linear dynamic range (LDR) or photosensitivity linearity (typically quoted in $\mathrm{dB}$ ), which is another device performance parameter used to evaluate PDs, of the pero-HPDs fabricated by the $\mathrm{CH}_{3} \mathrm{NH}_{3} \mathrm{PbI}_{3}: \mathrm{PbS}$ QDs nanocomposites thin film under external bias of $-1 \mathrm{~V}$, is estimated according to the equation of LDR $=20 \log \left(J_{p h}^{*} / J_{d}\right)$ [34], where $J_{p h}^{*}$ is the photocurrent measured at the light intensity of $1 \mathrm{~mW} / \mathrm{cm}^{2}$. At room temperature, the LDR is $95 \mathrm{~dB}$ for the pero-HPDs fabricated by the $\mathrm{CH}_{3} \mathrm{NH}_{3} \mathrm{PbI}_{3}: \mathrm{PbS}$ QDs nanocomposites thin film, which is significantly higher than that (66 dB, at 4.2K) from InGaAs PDs [42].

The temporal responses of the photocurrent of pero-HPDs are evaluated by using an optical chopper controlled at $\lambda=532 \mathrm{~nm}$ laser pulse at a frequency of $1 \mathrm{kHz}$, the results are shown in Fig. 5a,b. The pero-HPDs fabricated by the $\mathrm{CH}_{3} \mathrm{NH}_{3} \mathrm{PbI}_{3}$ thin film shows bi-exponential photocurrent decay with a time constant of $1.1 \mu$ s for the fast component and $26.1 \mu$ s for the slow component, which indicate two recombination pathways for the trapped electrons. In contrast, the pero-HPDs fabricated by the $\mathrm{CH}_{3} \mathrm{NH}_{3} \mathrm{PbI}_{3}: \mathrm{PbS}$ QDs nanocomposites thin film shows much longer decay time of $11.5 \mu \mathrm{s}$ and $34.0 \mu \mathrm{s}$ for the fast and slow component, respectively. Since the decay time should be limited by the charge trapping and de-trapping processes, the slower photocurrent decay of the pero-HPDs fabricated by the $\mathrm{CH}_{3} \mathrm{NH}_{3} \mathrm{PbI}_{3}: \mathrm{PbS}$ QDs nanocomposites thin film is originated from the increased trap states with the introduction of $\mathrm{PbS}$ QDs, which is consistent with the results shown in Fig. 1. The photo-gains of the pero-HPDs fabricated by either the $\mathrm{CH}_{3} \mathrm{NH}_{3} \mathrm{PbI}_{3}$ thin film or the $\mathrm{CH}_{3} \mathrm{NH}_{3} \mathrm{PbI}_{3}: \mathrm{PbS}$ QDs nanocomposites thin film are determined by the recombination lifetime and charge transit time, following the equation of $\mathrm{G}=\frac{\tau_{\text {lifetime }}}{\tau_{\text {transit time }}}=$ $\frac{\tau_{\text {lifetime }}}{d^{2} / \mu \mathrm{V}}$, where $\mathrm{G}$ is the photo-gain, $\mathrm{d}$ is the thin film thickness, $\mu$ is the charge carrier mobility (hole mobility in this case), $\mathrm{V}$ is the applied bias and $\tau_{\text {lieftime }}$ is the charge carrier lifetime. The 
hole mobility of the $\mathrm{CH}_{3} \mathrm{NH}_{3} \mathrm{PbI}_{3}$ thin film and the $\mathrm{CH}_{3} \mathrm{NH}_{3} \mathrm{PbI}_{3}: \mathrm{PbS}$ QDs nanocomposites thin film estimated from the space-charge limited current measurement (Fig. S5, SI) are $5.2 \times 10^{-4} \mathrm{~cm}^{2}$ $\mathrm{V}^{-1} \mathrm{~s}^{-1}$ and $1.1 \times 10^{-3} \mathrm{~cm}^{2} \mathrm{~V}^{-1} \mathrm{~s}^{-1}$, respectively. The higher hole mobility from the $\mathrm{CH}_{3} \mathrm{NH}_{3} \mathrm{PbI}_{3}: \mathrm{PbS}$ QDs nanocomposites thin film could be elaborated by the GIWAX patterns shown in Fig. 3, the finer perovskite crystals with reduced low-dimensional defects in the $\mathrm{CH}_{3} \mathrm{NH}_{3} \mathrm{PbI}_{3}: \mathrm{PbS}$ QDs thin film tends to improve the hole mobility [43]. The carrier recombination lifetime and thickness of the $\mathrm{CH}_{3} \mathrm{NH}_{3} \mathrm{PbI}_{3}$ and the $\mathrm{CH}_{3} \mathrm{NH}_{3} \mathrm{PbI}_{3}: \mathrm{PbS}$ QDs thin films are $1.1 \mu \mathrm{s}, 11.5 \mu \mathrm{s}$ and $\sim 220 \mathrm{~nm}$, $\sim 250 \mathrm{~nm}$, respectively. Therefore, under the external bias of $-2 \mathrm{~V}$, the calculated photo-gain of the pero-HPDs fabricated by either the $\mathrm{CH}_{3} \mathrm{NH}_{3} \mathrm{PbI}_{3}$ thin film or the $\mathrm{CH}_{3} \mathrm{NH}_{3} \mathrm{PbI}_{3}: \mathrm{PbS}$ QDs nanocomposites thin film are 2.6 and 37.1, respectively, which are close to the gained values shown in the EQE (Fig. 2a).

\section{Conclusion}

In summary, we reported ultrasensitive pero-HPDs with high photo-gain under low drivingvoltages by introducing $\mathrm{PbS}$ QDs into $\mathrm{CH}_{3} \mathrm{NH}_{3} \mathrm{PbI}_{3}$ sensitizer. The $\mathrm{PbS}$ QDs, which induce additional trap-state onto the surface of the $\mathrm{CH}_{3} \mathrm{NH}_{3} \mathrm{PbI}_{3}$ thin film, could down-shift the LUMO energy level of the $\mathrm{CH}_{3} \mathrm{NH}_{3} \mathrm{PbI}_{3}$ thin film and adjust the energy level alignment at the $\mathrm{CH}_{3} \mathrm{NH}_{3} \mathrm{PbI}_{3} / \mathrm{Al}$ cathode interface, thus forming the ohmic contact for energy barrierless holeinjection from the $\mathrm{Al}$ cathode. As a result, the pero-HPDs fabricated by the $\mathrm{CH}_{3} \mathrm{NH}_{3} \mathrm{PbI}_{3}: \mathrm{PbS}$ QDs nanocomposites thin film reaches an EQE of $\sim 4500 \%$, a high $\mathrm{R}$ of $\sim 15000 \mathrm{~mA} / \mathrm{W}$ and $D^{*}$ of $\sim 6 \times 10^{13}$ Jones at low voltage $(-2 \mathrm{~V})$ at room temperature, which are among the highest $\mathrm{R}$ and $D^{*}$ reported so far.

\section{Experimental section}




\subsection{Materials}

$\mathrm{PC}_{61} \mathrm{BM}(99.5 \%)$ was purchased from Solenne BV and used as received without further treatment. Lead iodide $\left(\mathrm{PbI}_{2}, 99.999 \%\right)$, anhydrous $N, N$-dimethylformamide (DMF), anhydrous chlorobenzene (CB, 99.8\%), bathocuproine (BCP, 99.99\%), hydroiodic acid (HI, 99.99\%), anhydrous methylamine lead $\left(\mathrm{CH}_{3} \mathrm{NH}_{2},>98 \%\right)$, oxide (PbO, 99.999\%)), 1-octadecene (ODE, >95\%), oleic acid (OA, >99\%), hexamethyldisilathiane (TMS), anhydrous hexane (95\%), anhydrous octane (>99\%) and anhydrous toluene $(99.8 \%)$ were purchased from Sigma-Aldrich and used as received. Methylammonium iodide (MAI, $\left.\mathrm{CH}_{3} \mathrm{NH}_{3} \mathrm{I}\right)$ was synthesized by $\mathrm{HI}$ and $\mathrm{CH}_{3} \mathrm{NH}_{2}$ in our laboratory [44].

\subsection{Synthesis of OA-capped PbS QDs}

The PbS QDs are synthesized according to the method reported in literatures [45]. In brief, $0.446 \mathrm{~g}$ of $\mathrm{PbO}, 13.5 \mathrm{~mL}$ of $\mathrm{ODE}$ and $5.07 \mathrm{~mL}$ of $\mathrm{OA}$ were mixed and stirred at $120{ }^{\circ} \mathrm{C}$ for 1 hour under vacuum, followed by heating up to $150^{\circ} \mathrm{C}$. After quickly injection of $210 \mu \mathrm{L}$ of TMS mixed with $5 \mathrm{~mL}$ of ODE into the previous solution, the reaction was stopped after 1 minute reaction and then cooled down to room temperature. Afterwards, under the stirring, $5 \mathrm{~mL}$ of hexane and $15 \mathrm{~mL}$ of acetone were added into the above solution in sequence. The mixed solution was then centrifuged for 20 minutes. After discarding the supernatant, the product was washed by $5 \mathrm{~mL}$ of hexane and $7 \mathrm{~mL}$ of acetone, followed with another 15 minutes centrifugation. After discarding the supernatant again and drying the resultant product, the OAcapped PbS QDs powders were produced. Finally, the PbS QDs were dispersed into hexane with a concentration of $10 \mathrm{mg} / \mathrm{mL}$ for future use.

\subsection{Ligand exchange of PbS QDs}


In order to enhance the electrical conductivity of $\mathrm{PbS} \mathrm{QDs}$, the $\mathrm{OA}$ ligand is exchanged to iodide in solution according to the reported method [46]. Firstly, $3 \mathrm{~mL}$ OA-capped PbS QDs was dispersed into octane $(10 \mathrm{mg} / \mathrm{mL})$. After stirring above solution for 10 minutes, a phase separation is appeared. Secondly, discarding the top octane phase and then washing PbS QDs solution three times by octane to remove the excess organic residue. Afterwards, adding toluene to precipitate $\mathrm{PbS} \mathrm{QDs}$, and then drying the resultant powders. Finally, dissolving the iodidecapped $\mathrm{PbS}$ QDs into perovskite precursor solution $\left(\mathrm{PbI}_{2}: \mathrm{CH}_{3} \mathrm{NH}_{3} \mathrm{I}\right.$ with a molar ratio of 1:1 in DMF with a concentration of $300 \mathrm{mg} / \mathrm{mL}$ ) to stabilize PbS QDs.

\subsection{Fabrication of pero-HPDs}

$\sim 40 \mathrm{~nm}$ thick PEDOT:PSS layer is spin-coated onto pre-cleaned and UV-treated ITO substrates, followed with thermal-annealing at $150^{\circ} \mathrm{C}$ for 10 minutes in air and then transferred into the glovebox with nitrogen atmosphere. After preheating the ITO/PEDOT:PSS substrate at $70{ }^{\circ} \mathrm{C}$ for 5 minutes, $\sim 220 \mathrm{~nm}$ thick $\mathrm{CH}_{3} \mathrm{NH}_{3} \mathrm{PbI}_{3}$ or $\sim 250 \mathrm{~nm}$ thick $\mathrm{CH}_{3} \mathrm{NH}_{3} \mathrm{PbI}_{3}: \mathrm{PbS}$ QDs nanocomposites active layer is fabricated from corresponding solutions (the $\mathrm{PbI}_{2}: \mathrm{CH}_{3} \mathrm{NH}_{3} \mathrm{I}$ solution or the $\mathrm{PbI}_{2}: \mathrm{CH}_{3} \mathrm{NH}_{3} \mathrm{I}: \mathrm{PbS}$ QDs solution with a weight ratio of $\mathrm{PbI}_{2}: \mathrm{PbS}$ QDs=30:2). After thermal annealing the active layer at $100{ }^{\circ} \mathrm{C}$ for 10 minutes, $\sim 20 \mathrm{~nm}$ thick $\mathrm{PC}_{61} \mathrm{BM}$ layer is spin-casted from $20 \mathrm{mg} / \mathrm{mL} \mathrm{CB}$ solution. Afterwards, $8 \mathrm{~nm}$ thick $\mathrm{BCP}$ and $100 \mathrm{~nm}$ thick aluminum (Al) are thermally deposited through a shadow mask in the vacuum with the press of $4 \times 10^{-6} \mathrm{mbar}$. The device area is measured to be $0.045 \mathrm{~cm}^{2}$.

\subsection{Thin film characterizations}

The t-DOS of either the $\mathrm{CH}_{3} \mathrm{NH}_{3} \mathrm{PbI}_{3}$ thin film or the $\mathrm{CH}_{3} \mathrm{NH}_{3} \mathrm{PbI}_{3}: \mathrm{PbS}$ QDs nanocomposites (weight ratio 30:2 and 30:1) thin film were characterized by Keithley model 82-WIN Simultaneous CV System. The GIWAX spectra were carried out in the beamline 8-ID-E, 
Advanced Photon Source, Argonne National Laboratory. The SEM images were conducted on field emission SEM equipment (Model JEOL-7401, Japanese electron optics laboratory (JEOL)).

\subsection{Device characterizations}

The J-V characteristics of pero-HPDs were carried out on a Keithley model 2400 source measure unit in dark, under white light and monochromatic light at wavelength $(\lambda)$ of $500 \mathrm{~nm}$ illumination. The light intensities for white light and the light at $\lambda=500 \mathrm{~nm}$ are $100 \mathrm{mWcm}^{-2}$ and $1.15 \mathrm{mWcm}^{-2}$, respectively. The EQE spectra of pero-HPDs were obtained by using the solar cell quantum efficiency measurement system (QEX10) from PV measurements with a $300 \mathrm{~W}$ steadystate xenon lamp as the source light. The transient photocurrent measurements were performed by using an optical chopper controlled at $\lambda=532 \mathrm{~nm}$ laser pulse at a frequency of $2 \mathrm{kHz}$.

\section{Acknowledgements}

The authors acknowledge National Science Foundation (EECS 1351785) and Air Force Scientific Research (FA9550-15-1-0292) for financial supports. CL thank Dr. Zhang Jiang at Argonne National Laboratory for assistance with the GIWAXS measurements through the U.S. Department of Energy, Office of Science, Office of Basic Energy Sciences, under Contract DEAC02-06CH11357. 


\section{References}

[1] M. Houssa, M. Tuominen, M. Naili, V. Afanas' ev, A. Stesmans, S. Haukka, M.M. Heyns, J. Appl. Phys. 87 (2000) 8615-8620.

[2] A.I. Chou, K. Lai, K. Kumar, P. Chowdhury, J.C. Lee, Appl. Phys. Lett. 70 (1997) 34073409.

[3] H.Y. Chen, M.K. Lo, G. Yang, H.G. Monbouquette, Y. Yang, Nat. Nanotechnol. 3 (2008) $543-547$.

[4] L. Li, F. Zhang, W. Wang, Q. An, J. Wang, Q. Sun, M. Zhang, ACS Appl. Mater. Interfaces 7 (2015) 5890-5897.

[5] F. Guo, B. Yang, Y. Yuan, Z. Xiao, Q., Y. Bi, J. Huang, Nat. Nanotechnol. 7 (2012) 798802.

[6] W. Wang, F. Zhang, L. Li, M. Zhang, Q. An, J. Wang, Q. Sun, J. Mater. Chem. C 3 (2015) 7386-7393.

[7] R. Dong, C. Bi, Q. Dong, F. Guo, Y. Yuan, Y. Fang, Z. Xiao, J. Huang, Adv. Opt. Mater. 2 (2014) 549-554.

[8] H. Wei, Y. Fang, Y. Yuan, L. Shen, J. Huang, Adv. Mater. 27 (2015) 4975-4981.

[9] L. Li, F. Zhang, J. Wang, Q. An, Q. Sun, W. Wang, J. Zhang, F. Teng, Sci. Rep. 5 (2105) 9181.

[10] A. Mei, X. Li, L. Liu, Z. Ku, T. Liu, Y. Rong, M. Xu, M. Hu, J. Chen, Y. Yang, M. Grätzel, H. Han, Science 345 (2014) 295-298.

[11] L. Etgar, P. Gao, Z. Xue, Q. Peng, A.K. Chandiran, B. Liu, M.K. Nazeeruddin, M. Grätzel, J. Am. Chem. Soc. 134 (2012) 17396-17399. 
[12] M.M. Lee, J. Teuscher, T. Miyasaka, T.N. Murakami, H.J. Snaith, Science 338 (2012) 643-647.

[13] H. Zhou, Q. Chen, G. Li, S. Luo, T.B. Song, H.S. Duan, Z. Hong, J. You, Y. Liu, Y. Yang, Science 345(2014) 542-546.

[14] J. Xu, A. Buin, A.H. Ip, W. Li, O. Voznyy, R. Comin, M. Yuan, S. Jeon, Z. Ning, J.J. McDowell, P. Kanjanaboos, Nat. Commun. 6 (2015) 7081.

[15] C. Liu, K. Wang, P. Du, C. Yi, T. Meng, X. Gong, Adv. Energy Mater. 5 (2015) DOI: $10.1002 /$ aenm.201402024.

[16] G.J.A. Wetzelaer, M. Scheepers, A.M. Sempere, C. Momblona, J. Ávila, H.J. Bolink, Adv. Mater. 27 (2015) 1837-1841.

[17] Y. Shao, Z. Xiao, C. Bi, Y. Yuan, J. Huang, Nat. Commun. 5 (2014) 5784.

[18] J.H. Heo, D.H. Song, H.J. Han, S.Y. Kim, J.H. Kim, D. Kim, H.W. Shin, T.K. Ahn, C. Wolf, T.-W. Lee, S.H. Im, Adv. Mater. 27 (2015) 3424-3430.

[19] J.H. Park, J. Seo, S. Park, S.S. Shin, Y.C. Kim, N.J. Jeon, H.-W. Shin, T.K. Ahn, J.H Noh, S.C. Yoon, C.S. Hwang, S.I. Seok, Adv. Mater. 27 (2015) 4013-4019.

[20] A.H. Ip, S.M. Thon, S. Hoogland, O. Voznyy, D. Zhitomirsky, R. Debnath, L. Levina, L.R. Rollny, G.H. Carey, A. Fischer, K.W. Kemp, Nat. Nanotechnol. 7 (2012) 577-582.

[21] J. Tang, K.W. Kemp, S. Hoogland, K.S. Jeong, H. Liu, L. Levina, M. Furukawa, X. Wang, R. Debnath, D. Cha, K.W. Chou, Nat. Mater. 10 (2011) 765-771.

[22] G. Konstantatos, E.H. Sargent, Appl. Phys. Lett. 91 (2007) 173505.

[23] R. Dong, Y. Fang, J. Chae, J. Dai, Z. Xiao, Q. Dong, Y. Yuan, A. Centrone, X.C. Zeng, J. Huang, Adv. Mater. 27 (2015) 1912-1918. 
[24] P.R. Brown, D. Kim, R.R. Lunt, N. Zhao, M.G. Bawendi, J.C. Grossman, V. Bulović, ACS Nano 8 (2014) 5863-5872.

[25] I. Moreels, K. Lambert, D. Smeets, D. De Muynck, T. Nollet, J.C. Martins, F. Vanhaecke, A. Vantomme, C. Delerue, G. Allan, Z. Hens, ACS Nano 3 (2009) 3023-3030.

[26] Y. Shao, Y. Yuan, J. Huang, Nat. Energy 1 (2016) 15001.

[27] J. Bisquert, Phys. Chem. Chem. Phys. 10 (2008) 3175-3194.

[28] T. Agostinelli, M. Campoy-Quiles, J.C. Blakesley, R. Speller, D.D.C. Bradley, J. Nelson, Appl. Phys. Lett. 93 (2008) 203305.

[29] P.E. Keivanidis, P.K. Ho, R.H. Friend, N.C. Greenham, Adv. Funct. Mater. 20 (2010) 3895-3903.

[30] J.C. Scott, G.G. Malliaras, Chem. Phys. Lett. 299 (1999) 115-119.

[31] J. Gao, S. Jeong, F. Lin, P.T. Erslev, O.E. Semonin, J.M. Luther, M.C. Beard, Appl. Phys. Lett. 102 (2013) 043506.

[32] J. Akhtar, M.A. Malik, P. O'Brien, K.G.U. Wijayantha, R. Dharmadasa, S.J. Hardman, D.M. Graham, B.F. Spencer, S.K. Stubbs, W.R. Flavell, D.J. Binks, J. Mater. Chem. 20 (2010) 2336-2344.

[33] C. Liu, K. Wang, C. Yi, X. Shi, A.W. Smith, X. Gong, A.J. Heeger, Adv. Funct. Mater. 26 (2016) 101-110.

[34] X. Gong, M. Tong, Y. Xia, W. Cai, J.S. Moon, Y. Cao, G. Yu, C.L. Shieh, B. Nilsson, A.J. Heeger, Science 325 (2009) 1665-1667.

[35] OSI

Optoelectronics, http://www.osioptoelectronics.com/Libraries/Datasheets/PhotovoltaicPhotodiodes.sflb.ashx. 
[36] L. Dou, Y.M. Yang, J.You, Z. Hong, W.H. Chang, G. Li, Y. Yang, Nat. Commun. $5(2014) 5404$.

[37] C. Liu, K. Wang, C. Yi, X. Shi, P. Du, A.W. Smith, A. Karim, X. Gong, J. Mater. Chem. C 3 (2015) 6600-6606.

[38] Y. Fang, J. Huang, Adv. Mater. 27 (2015) 2804-2810.

[39] B.R. Sutherland, A.K. Johnston, A.H. Ip, J. Xu, V. Adinolfi, P. Kanjanaboos, E.H. Sargent, ACS Photon. 2 (2015) 1117-1123.

[40] X. Hu, X. Zhang, L. Liang, J. Bao, S. Li, W. Yang, Y. Xie, Adv. Funct. Mater. 24 (2014) 7373-7380.

[41] C. Liu, K. Wang, P. Du, E. Wang, X. Gong, A.J. Heeger, Nanoscale 7 (2015) 1646016469.

[42] G. Konstantatos, I. Howard, A. Fischer, S. Hoogland, J. Clifford, E. Klem, L. Levina, E.H. Sargent, Nature 442 (2006) 180-183.

[43] S.D. Stranks, G.E. Eperon, G. Grancini, C. Menelaou, M.J. Alcocer, T. Leijtens, L.M. Herz, A. Petrozza, H.J. Snaith, Science 342 (2013) 341-344.

[44] D. Shi, V. Adinolfi, R. Comin, M. Yuan, E. Alarousu, A. Buin, Y. Chen, S. Hoogland, A. Rothenberger, K. Katsiev, Y. Losovyj, Science 347 (2015) 519-522.

[45] M.A. Hines, G.D. Scholes, Adv. Mater. 15 (2013) 1844-1849.

[46] Z. Ning, X. Gong, R. Comin, G. Walters, F. Fan, O. Voznyy, E. Yassitepe, A. Buin, S. Hoogland, E.H. Sargent, Nature 523 (2015) 324-328. 
Table 1. Device parameters of pero-HPDs

\begin{tabular}{|c|c|c|c|c|c|}
\hline $\begin{array}{c}\text { Active layer of } \\
\text { PDs }\end{array}$ & $\begin{array}{c}\text { External bias } \\
\text { (V) }\end{array}$ & $\begin{array}{c}\mathbf{J}_{\mathbf{p h}} \\
\left(\mathbf{m A} / \mathbf{c m}^{2}\right)\end{array}$ & $\begin{array}{c}\mathbf{J}_{\mathbf{d}} \\
\left(\mathrm{mA} / \mathrm{cm}^{2}\right)\end{array}$ & $\begin{array}{c}\mathbf{R} \\
(\mathrm{mA} / \mathrm{W})\end{array}$ & $\begin{array}{c}\mathrm{D}^{*} \\
\text { (Jones) }\end{array}$ \\
\hline \multirow{4}{*}{$\mathrm{CH}_{3} \mathbf{N H}_{3} \mathrm{PbI}_{3}$} & -0.5 & $4.1 \times 10^{-1}$ & $1.5 \times 10^{-4}$ & 350 & $1.5 \times 10^{12}$ \\
\hline & -1 & $7.2 \times 10^{-1}$ & $8.2 \times 10^{-4}$ & 620 & $1.3 \times 10^{12}$ \\
\hline & -2 & $9.6 \times 10^{-1}$ & $2.1 \times 10^{-3}$ & 870 & $9.1 \times 10^{11}$ \\
\hline & -0.5 & $1.6 \times 10^{0}$ & $1.5 \times 10^{-5}$ & 1390 & $1.6 \times 10^{13}$ \\
\hline $\mathrm{CH}_{3} \mathbf{N H}_{3} \mathrm{PbI}_{3}: \mathrm{PbS}$ & -1 & $3.8 \times 10^{0}$ & $8.1 \times 10^{-5}$ & 3300 & $2.1 \times 10^{13}$ \\
\hline QDs & -2 & $9.8 \times 10^{0}$ & $7.4 \times 10^{-4}$ & 8520 & $1.7 \times 10^{13}$ \\
\hline${ }^{\S} \mathbf{S i}$ & - & - & $\sim 2.0 \times 10^{-7}$ & $\begin{array}{l}600 \\
\sim 60\end{array}$ & $\sim 10^{13}$ \\
\hline
\end{tabular}

For pero-HPDs, $\mathrm{J}_{\mathrm{ph}}, \mathrm{R}$ and $\mathrm{D}^{*}$ were measured and calculated under the illumination of monochromatic light at $\lambda=500 \mathrm{~nm}$ with a light intensity of $1.15 \mathrm{~mW} / \mathrm{cm}^{2} .{ }^{\S}$ For Si-based PDs, $\mathrm{J}_{\mathrm{d}}$ is measured under external bias of $-5 \mathrm{~V}, \mathrm{R}$ is the general value in the wavelength region from $500 \mathrm{~nm}$ to $1000 \mathrm{~nm}, \mathrm{D}^{*}$ is the general value in the whole visible to NIR region. The maximum external bias for the Si-based PDs is $-5 \mathrm{~V}$. 


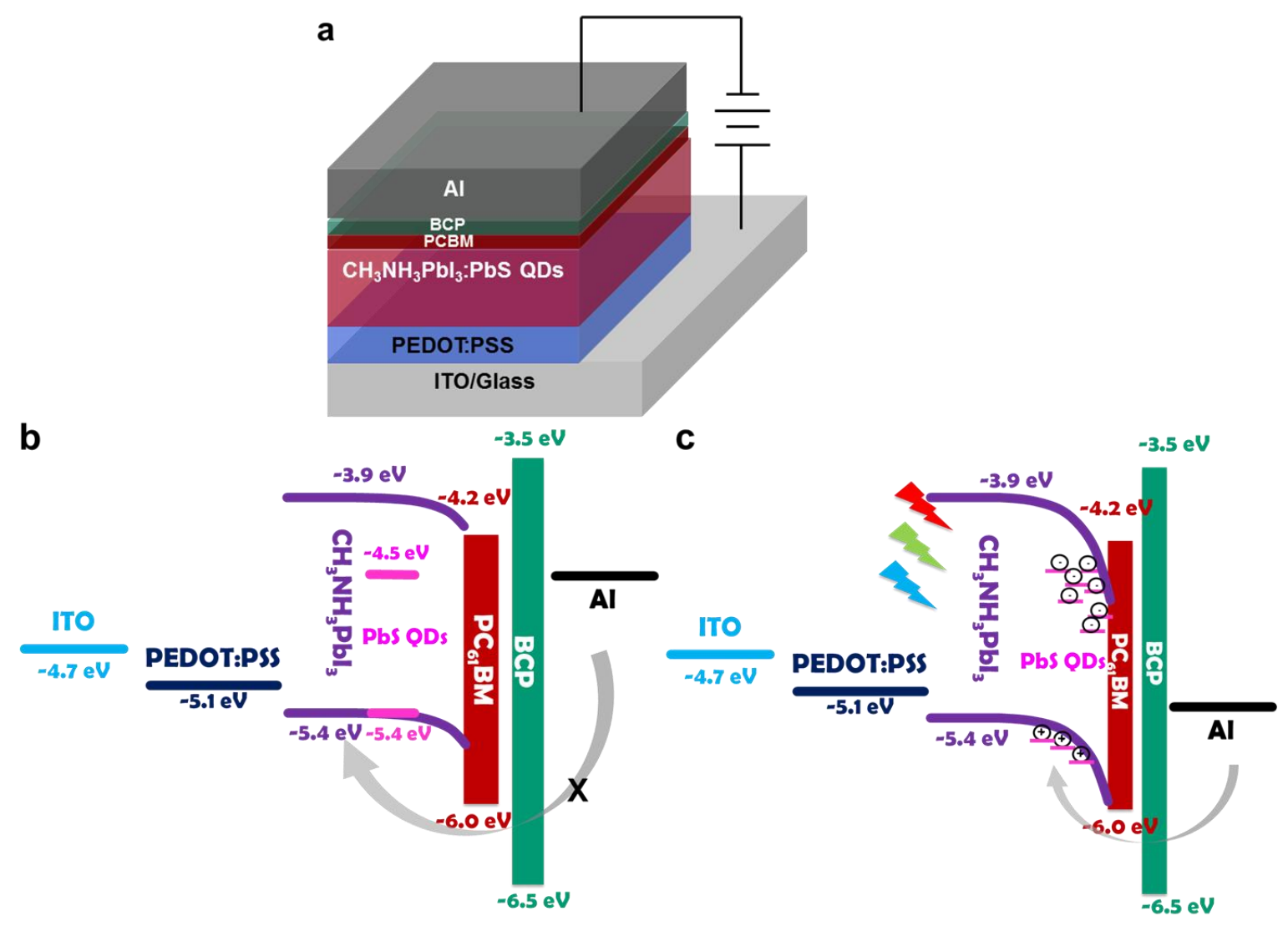

Scheme 1. Device structure and proposed working mechanisms of pero-HPDs. (a) Device structure of perovskite hybrid photodetectors (pero-HPDs); and energy level alignment of the materials used for fabrication of pero-HPDs (b) in dark and (c) under illumination. 

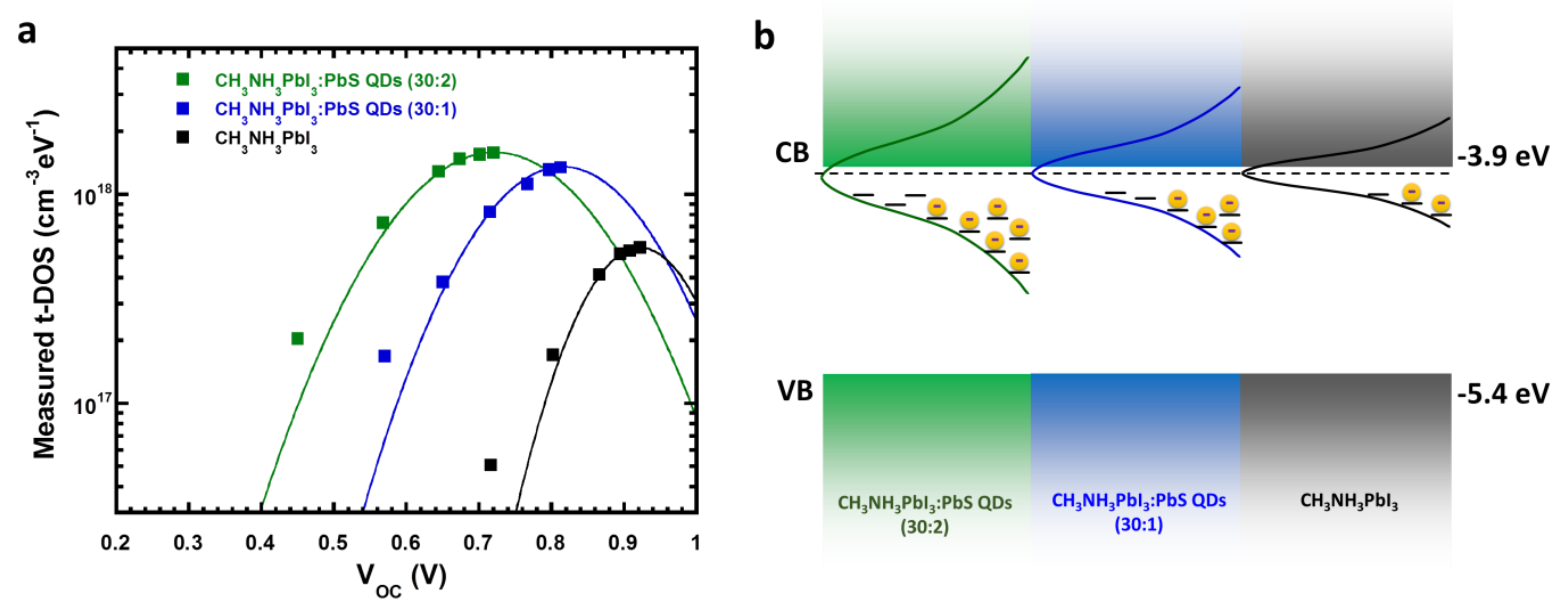

Fig. 1. Trap density of states (t-DOS) study. (a) t-DOS of the $\mathrm{CH}_{3} \mathrm{NH}_{3} \mathrm{PbI}_{3}, \mathrm{CH}_{3} \mathrm{NH}_{3} \mathrm{PbI}_{3}: \mathrm{PbS}$ QDs (weight ratio 30:1) nanocomposites and $\mathrm{CH}_{3} \mathrm{NH}_{3} \mathrm{PbI}_{3}$ : $\mathrm{PbS}$ QDs (weight ratio 30:2) nanocomposites thin films; (b) Schematic illustration of in-gap energy level distribution in the $\mathrm{CH}_{3} \mathrm{NH}_{3} \mathrm{PbI}_{3}, \mathrm{CH}_{3} \mathrm{NH}_{3} \mathrm{PbI}_{3}: \mathrm{PbS}$ QDs (weight ratio 30:1) nanocomposites and $\mathrm{CH}_{3} \mathrm{NH}_{3} \mathrm{PbI}_{3}: \mathrm{PbS}$ QDs (weight ratio 30:2) nanocomposites thin films. 

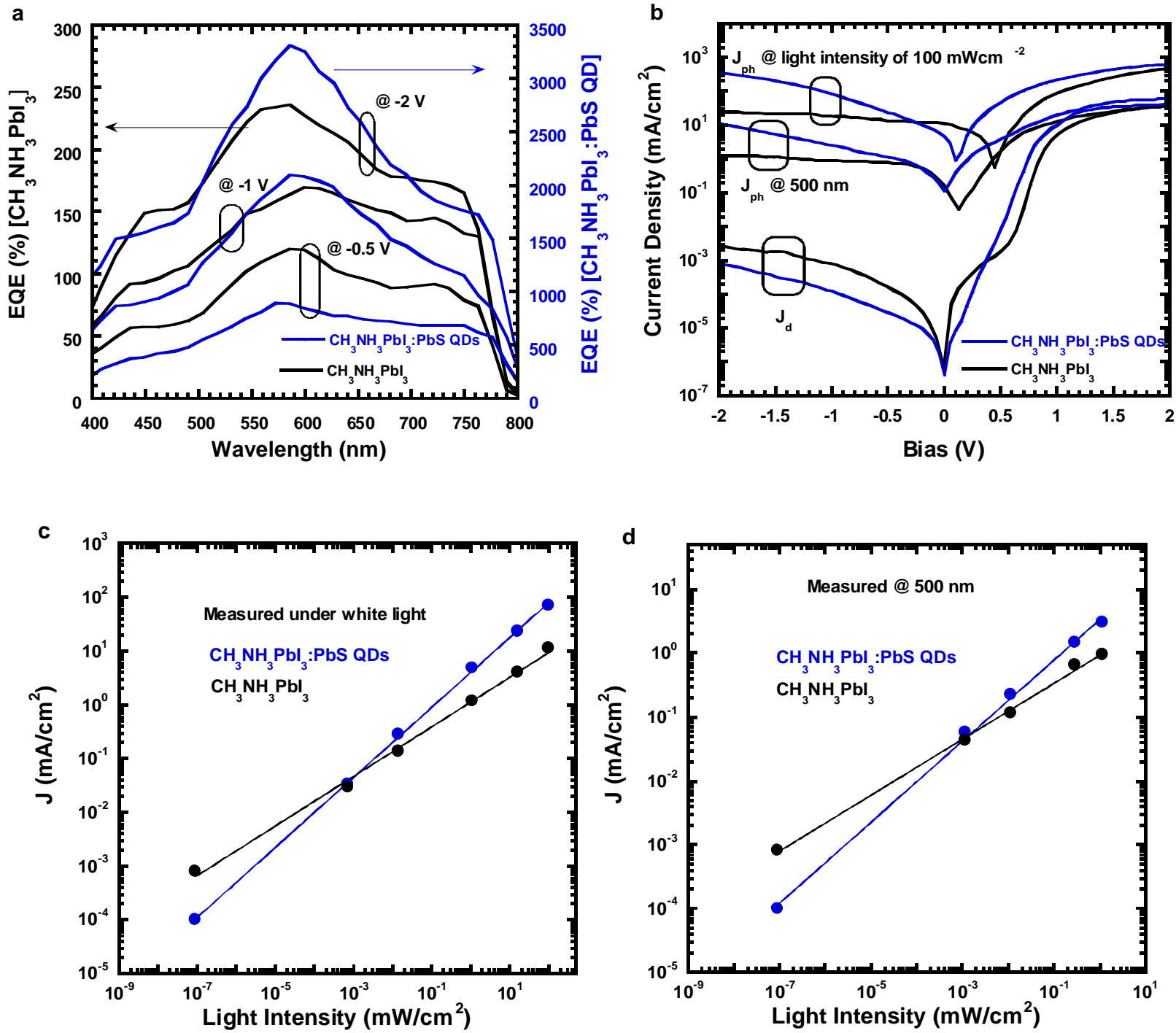

Fig. 2. Photo-gains of pero-HPDs. (a) External quantum efficiency (EQE) spectra of the peroHPDs fabricated by the and pero-HPDs fabricated by the $\mathrm{CH}_{3} \mathrm{NH}_{3} \mathrm{PbI}_{3}$ : $\mathrm{PbS}$ QDs nanocomposites thin film at different negative biases $(-0.5 \mathrm{~V},-1 \mathrm{~V}$ and $-2 \mathrm{~V})$; (b) $\mathrm{J}-\mathrm{V}$ characteristics of the pristine pero-HPDs and pero-HPDs fabricated by $\mathrm{CH}_{3} \mathrm{NH}_{3} \mathrm{PbI}_{3}: \mathrm{PbS}$ QDs nanocomposites thin film in dark, under illumination of white light with a light intensity of $100 \mathrm{~mW} / \mathrm{cm}^{2}$ and monochromatic light at $\lambda=500 \mathrm{~nm}$ with a light intensity of $1.15 \mathrm{~mW} / \mathrm{cm}^{2}$; Hole-injection current (J) under external bias of $-1 \mathrm{~V}$ as a function of various light intensity under (a) white light and (b) monochromatic light at $\lambda=500 \mathrm{~nm}$. 

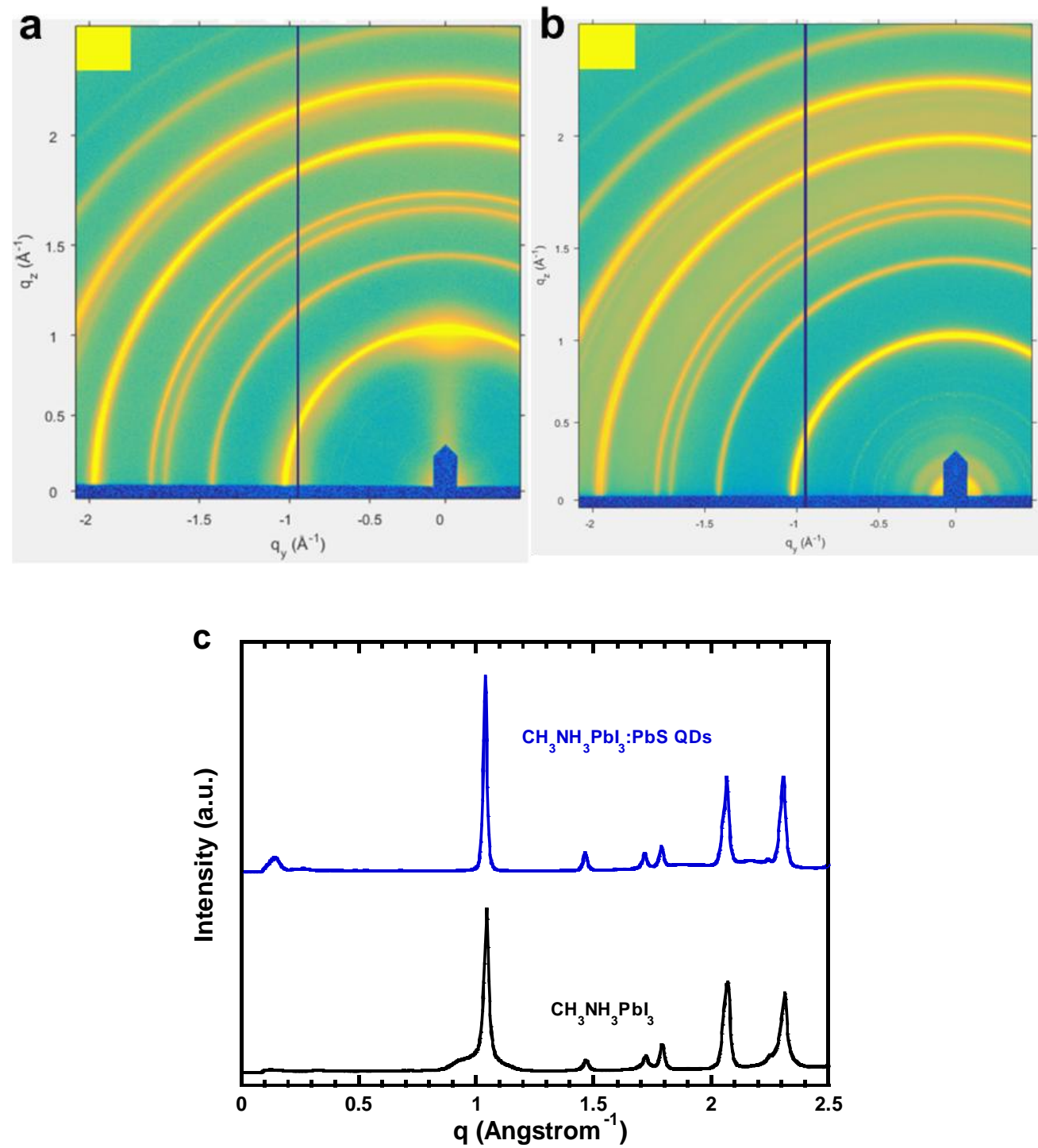

Fig. 3. Film morphologies of the $\mathrm{CH}_{3} \mathrm{NH}_{3} \mathrm{PbI}_{3}$ and $\mathrm{CH}_{3} \mathrm{NH}_{3} \mathrm{PbI}_{3}: \mathrm{PbS}$ QDs thin films. $2 \mathrm{D}$ GIWAX profile of (a) the $\mathrm{CH}_{3} \mathrm{NH}_{3} \mathrm{PbI}_{3}$ thin film and (b) the $\mathrm{CH}_{3} \mathrm{NH}_{3} \mathrm{PbI}_{3}: \mathrm{PbS}$ QDs nanocomposites thin film; (c) Azimuthally integrated intensity plots of the GIWAXS patterns. 

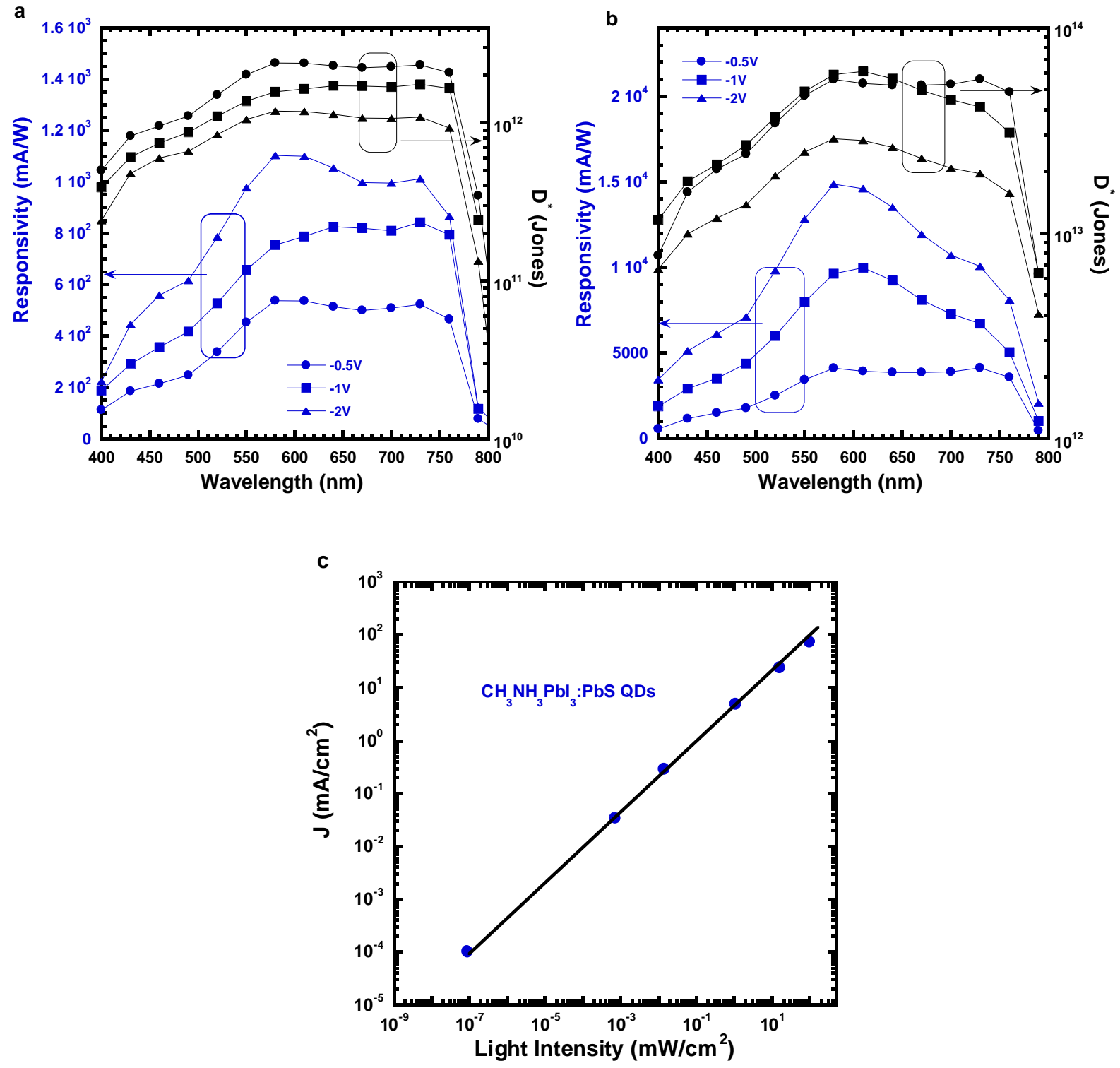

Fig. 4. Characterizations of pero-HPDs. Responsivity and detectivity versus wavelength spectra of (a) the pero-HPDs fabricated by the $\mathrm{CH}_{3} \mathrm{NH}_{3} \mathrm{PbI}_{3}$ thin film and (b) the pero-HPDs fabricated by the $\mathrm{CH}_{3} \mathrm{NH}_{3} \mathrm{PbI}_{3}: \mathrm{PbS}$ QDs nanocomposites thin film; (c) Linear dynamic range (LDR) of the pero-HPDs fabricated by $\mathrm{CH}_{3} \mathrm{NH}_{3} \mathrm{PbI}_{3}: \mathrm{PbS}$ QDs nanocomposites thin film at an external bias of $-1 \mathrm{~V}$. 

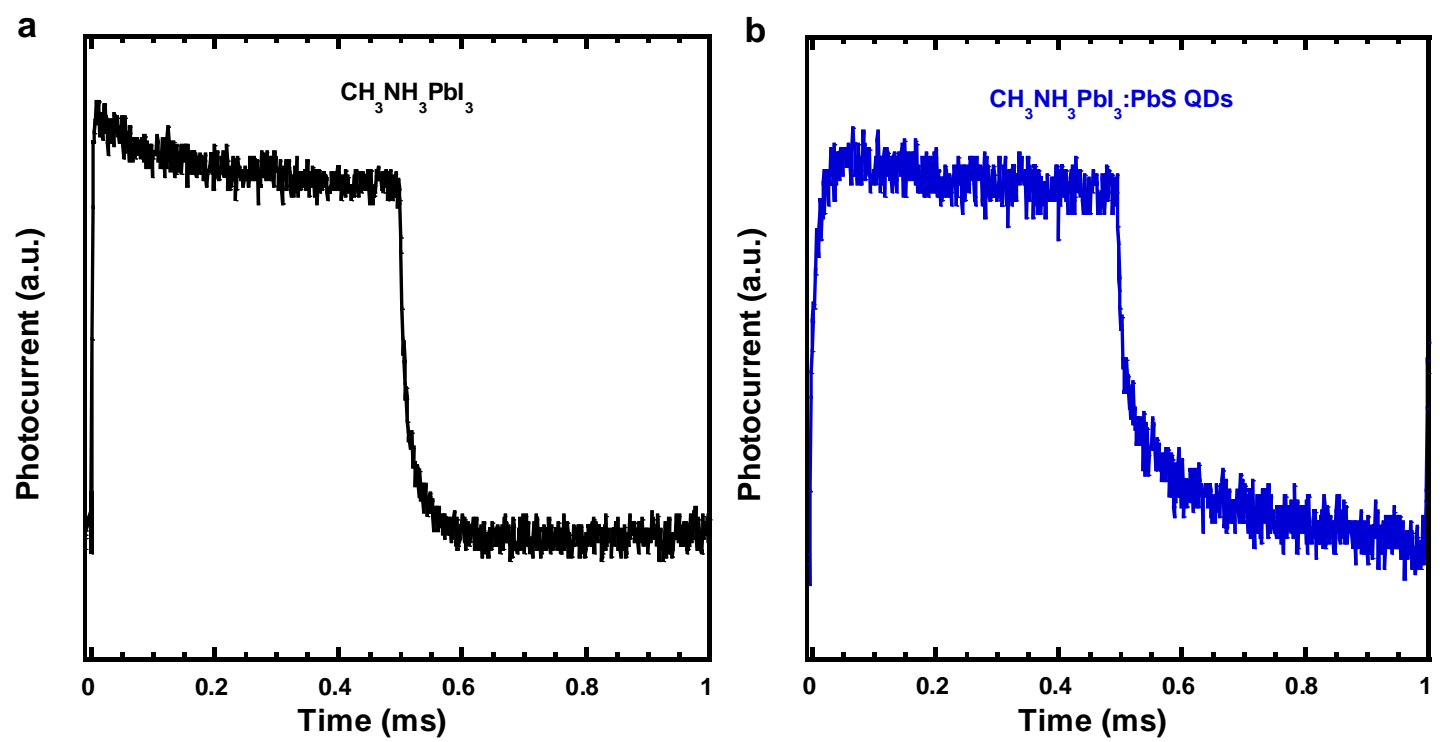

Fig. 5. Response time of pero-HPDs. The transient photocurrent of (a) the pero-HPDs fabricated by the $\mathrm{CH}_{3} \mathrm{NH}_{3} \mathrm{PbI}_{3}$ thin film and (b) the pero-HPDs fabricated by the $\mathrm{CH}_{3} \mathrm{NH}_{3} \mathrm{PbI}_{3}: \mathrm{PbS}$ QDs nanocomposites thin film measured with an optical chopper (frequency-- $1 \mathrm{kHz}$ ) controlled $\lambda=$ $532 \mathrm{~nm}$ laser pulse. 


\section{Graphical Abstract}

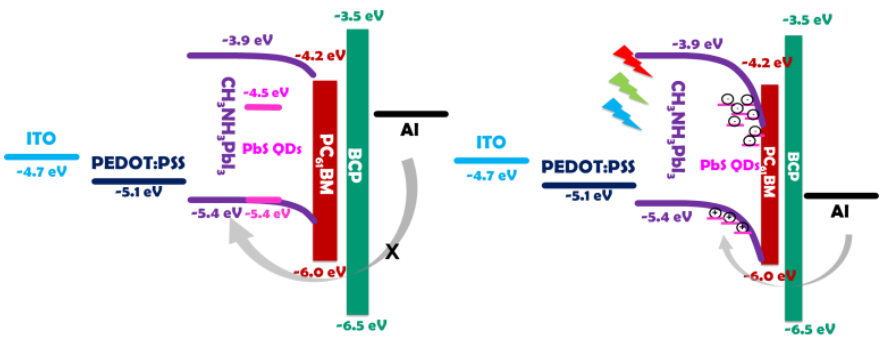

